\title{
Transmissão por Mãos Contaminadas e Ausência de Transmissão Embrionária do Vírus do Amarelo Letal do Mamoeiro*
}

\author{
Armando C. M. Saraiva ${ }^{1}$, Waldelice O. de Paiva ${ }^{2 * *}$, Francisco A. C. Rabelo Filho** \\ \& J. Albérsio A. Lima ${ }^{1 * *}$
}

${ }^{1}$ Universidade Federal do Ceará, Departamento de Fitotecnia, Laboratório de Virologia Vegetal, Fortaleza, CE,

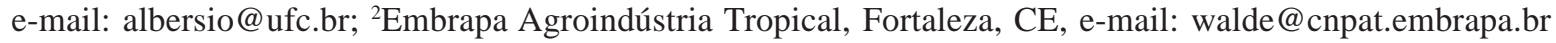

(Aceito para publicação em 16/09/2005)

Autor para correspondência: J. Albérsio A. Lima

SARAIVA, A.C.M., PAIVA, W.O., RABELO FILHO, F.A.C. \& LIMA, J.A.A. Transmissão por mãos contaminadas e ausência de transmissão embrionária do vírus do amarelo letal do mamoeiro. Fitopatologia Brasileira 31:079-083. 2006.

\section{RESUMO}

O vírus do amarelo letal do mamoeiro ("Papaya lethal yellowing virus”, PLYV) é responsável por uma das principais doenças do mamoeiro (Carica papaya) no Nordeste brasileiro. O PLYV pode ser transmitido por solo, água, instrumentos de corte contaminados e por inoculação mecânica em condições experimentais. Na presente pesquisa, avaliou-se a transmissão do PLYV por mãos contaminadas e sua presença em embriões de sementes de frutos infetados. O PLYV foi transmitido por mãos contaminadas, e mãos contaminadas e lavadas em água corrente revelando elevada estabilidade. Experimentos com 1.128 embriões de sementes obtidas de frutos infetados com o vírus revelaram a ausência do PLYV, cuja presença foi constatada em 112 tegumentos das 670 sementes analisadas. O PLYV não foi perpetuado por plantio direto de sementes, envolvendo 310 plântulas e 362 mudas, comprovando não ser o mesmo transmitido por semente de forma embrionária. De outra parte, a presença do PLYV foi comprovada por Elisa indireto em 49 de 456 sementes per si testadas.

Palavras-chave adidionais: Carica papaya, PLYV, Tombusviridae, Papaya lethal yelloing virus.

\begin{abstract}
Transmission by contaminated hands and absence of embryonary seed transmission of Papaya lethal yellowing virus The "Papaya lethal yellowing virus" (PLYV) is responsible for an important disease of papaya (Carica papaya) in Northeast Brazil. PLYV can be transmitted by soil, water and contaminated cutting instruments, as well as through mechanical inoculation. The objective of the present work was to evaluate the possibility of the virus transmission by contaminated hands, and its presence in the embryos of infected papaya fruit seeds. The virus was transmitted through contaminated hands, thus revealing that PLYV is very stable. Experiments with embryos from 1,128 seeds of infected fruits revealed the absence of PLYV in the embryos from seeds of infected fruits, although the virus was present in 112 out of the 670 seed peel samples analyzed. Direct planting of seeds from infected fruits, involving 310 seedlings and 362 plant-seedlings, did not perpetuate PLYV, demonstrating that the virus is not transmitted in the embryo of the seeds. On the other hand, PLYV was detected by indirect Elisa in 49 out of 456 seeds per si.
\end{abstract}

Additional keywords: Carica papaya, PLYV, Tombusviridae, Papaya lethal yelloing virus.

Com a expansão da cultura do mamoeiro (Carica papaya L.) em áreas irrigadas do Nordeste brasileiro, as infecções causadas por bactérias, fungos, nematóides e vírus podem trazer sérios problemas de ordem sanitária para a cultura (Camarço, 1997; Lima et al., 2001; Lima \& Lima, 2002a, 2002b). As viroses têm sido consideradas como as principais doenças do mamoeiro, ocasionando grandes perdas na sua produção (Lima et al, 2001; Lima \& Lima, 2002a, 2002b) e impossibilitando seu cultivo em áreas extensas, imprimindo um caráter itinerante ou nômade à cultura (Camarço et al., 1998; Lima et al., 2001; Lima \& Lima, 2002a, 2002b).

Dentre os principais vírus que infetam o mamoeiro,

\footnotetext{
*Parte da dissertação de Mestrado do primeiro autor. Universidade Federal do Ceará (2004).

**Bolsistas do CNPq
}

somente o vírus da mancha anelar do mamoeiro, tipo Papaya (Papaya ringspot virus, PRSV-P), família Potyviridae, gênero Potyvirus; o vírus do amarelo letal do mamoeiro ("Papaya lethal yellowing virus”, PLYV), possível família Tombusviridae, gênero Carmovirus e o vírus da meleira, sem definição taxonômica foram registrados em pomares brasileiros (Camarço et al., 1998; Lima et al, 2001).

O PLYV é responsável por importante virose no mamoeiro (Kitajima et al., 1992a; Lima et al., 1994; Camarço et al., 1998; Lima et al., 2001; Lima \& Lima, 2002a, 2002b). O vírus possui partículas isométricas de aproximadamente $30 \mathrm{~nm}$ de diâmetro, com genoma do tipo ssRNA de ca. $1,6 \times 10^{6} \mathrm{Da}$, sendo o capsídeo formado por uma única proteína de ca. 35 Da (Kitajima et al., 1992a, 1992b; Camarço et al., 1998; Lima et al., 2001). É um provável membro da família Tombusviridae, gênero 
Carmovírus, embora estudos moleculares indiquem a possibilidade de o mesmo pertencer à família Sobemoviridae, gênero Sobemovirus (Silva, 1996; Silva et al., 2000).

Testes de transmissão do PLYV com os afídeos Aphis gossypii (Glover) e Mizus persicae Sulz e com besouros das espécies Diabrotica bivitulla Kirk e D. speciosa Kirk revelaram resultados negativos (Lima \& Santos, 1991; Silva, 1996; Camarço, 1997; Camarço et al., 1998). No entanto, o vírus pode ser transmitido de plantas de mamoeiro doentes para plantas sadias pelo método de transmissão mecânica, por enxertia, por ferramentas de cortes, por solos contaminados e por água de rega (Camarço et al., 1998; Lima et al., 2001).

Os sintomas do PLYV iniciam com o amarelecimento das folhas mais novas do terço superior da copa, que se tornam cloróticas, retorcidas, amarelecem, murcham e caem, induzindo a morte da planta. Os frutos apresentam pequenas manchas cloróticas (Figura 1). Todos estes sintomas já foram observados em mamoeiros naturalmente infetadas em diferentes campos de produção dos Estados do Ceará (Lima \& Santos, 1991; Lima et al., 2001), Paraíba (Camarço, 1997; Camarço et al., 1998), Pernambuco (Loreto et al., 1983) e Rio Grande do Norte (Kitajima et al., 1992a; 1992b; Teixeira, 1997).

O presente trabalho teve como objetivos avaliar a possibilidade da transmissão do PLYV por mãos contaminadas e por sementes obtidas de frutos infetados e verificar a presença do vírus no embrião e na casca das sementes.

\section{Estudo da transmissão e sobrevivência do PLYV em sementes de mamoeiro}

Sementes de frutos infetados pelo PLYV (Figura 1) foram retiradas e divididas em dois grupos: com e sem mucilagem. As sementes sem mucilagem foram lavadas em água corrente para a retirada da sarcotesta. Em seguida, os grupos de sementes foram postos, separadamente, em papel absorvente, para secagem durante 15 dias sob temperatura ambiente e sem incidência solar. Após esse período, foi realizada a análise da transmissão embrionária e sobrevivência do PLYV, através do teste das sementes per si e do teste de plantio direto, envolvendo plântulas e mudas desenvolvidas.

\section{Transmissão embrionária}

Teste de avaliação de plântulas: Um total de 310 sementes (136 com e 174 sem mucilagem) provenientes de frutos infetados com PLYV (Figura 1B) foi semeado em bandejas de isopor contendo solo e esterco esterilizados na proporção 3:1. Dez dias após a germinação, as plântulas foram testadas pela técnica de "enzyme-linked immunosorbant assay” (Elisa) indireto contra anti-soro para o PLYV (Almeida \& Lima, 2001).

Teste de Mudas: Para a deteç̧ão de possíveis sintomas do PLYV em mudas provenientes de sementes de
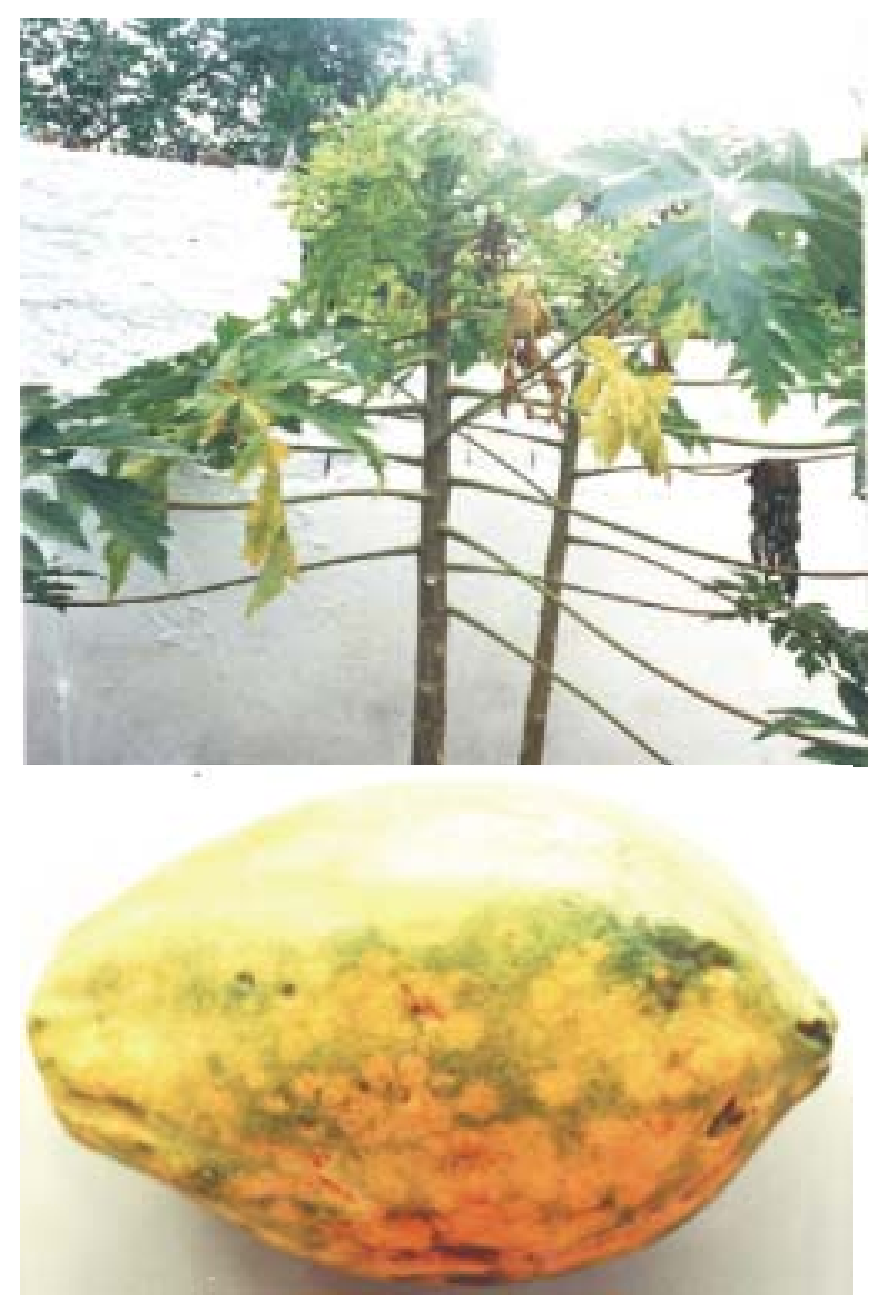

FIG. 1 - Sintomas típicos do vírus do amarelo letal do mamoeiro ("Papaya lethal yellowing virus", PLYV) em folhas e frutos de mamoeiro (Carica papaya). A) Terço superior da copa de plantas de mamoeiro infetadas pelo PLYV, com folhas cloróticas, retorcidas e amarelas; B) fruto de mamão infetado com PLYV, com manchas cloróticas.

frutos infetados, 362 sementes (210 com e 152 sem mucilagem) foram semeadas em bandejas de isopor e, 15 dias após a germinação, as plântulas foram transplantadas para sacos pretos de polietileno de 17 x $22 \mathrm{~cm}$ e $2 \mathrm{~mm}$, contendo solo e esterco esterilizados $\left(120{ }^{\circ} \mathrm{C} / 20 \mathrm{~min}\right)$ na proporção 3:1. Observações semanais foram realizadas, na expectativa de visualização dos sintomas da virose. Após 60 dias da germinação, amostras de tecidos foliares de todas as plantas, independente da sintomatologia, foram testadas por Elisa indireto.

Teste sorológico: Além de amostras de tecidos foliares e de frutos, sementes provenientes de frutos infetados (Figura 1) serviram como fonte de estudos para avaliação da presença do PLYV na sarcotesta ou tegumento e no embrião de sementes através de Elisa indireto. Os antígenos virais foram 
preparados em presença de tampão de cobertura (pH 9,6, 0,015 $\mathrm{M}$ de $\mathrm{Na}_{2} \mathrm{CO}_{3}, 0,035 \mathrm{M}$ de $\mathrm{NaHCO}_{3}$ e 0,007 $\mathrm{M}$ de dietil ditiocarbamato). Em seguida, foram colocados 100 ìl dos antígenos em cada orifício da placa de poliestireno que foi incubada por $1 \mathrm{~h}$ a $37^{\circ} \mathrm{C}$. Após lavagem com PBS-Tween $20\left(0,136 \mathrm{M}\right.$ de $\mathrm{NaCl}, 0,001 \mathrm{M}$ de $\mathrm{KH}_{2} \mathrm{PO}_{4}, 0,007 \mathrm{M}$ de $\mathrm{Na}_{2} \mathrm{HPO}_{4}$. $12 \mathrm{H}_{2} \mathrm{O}, 0,05 \%$ de Tween 20) e secagem, foram adicionados aos orifícios 100 il de anti-soro policlonal para o PLYV na diluição de 1:1.000, em tampão do anti-soro de PBS-Tween $(0,5 \mathrm{M}$ de polivenil pirrolidona, $2 \%$ de ovalbumina, 0,003 M de azida de sódio, 0,17\% de dietil ditiocabarmato) e as placas foram incubadas por $1 \mathrm{~h}$, a 37 ${ }^{\circ} \mathrm{C}$. Após nova secagem, a cada orifício adicionaram-se 100 ìl do conjugado universal de anti-imunoglobulina de coelho produzido em cabra, conjugado a fosfatase alcalina e diluído na proporção de 1:2.000 em tampão de 0,5 $\mathrm{M}$ de polivenil pirrolidona, 2\% de ovalbumina, 0,003 M de azida de sódio. Depois de $1 \mathrm{~h}$ de incubação a $37^{\circ} \mathrm{C}$ e nova secagem, foram adicionados 100 ìl do substrato $P$ - nitrofenil fosfato de sódio a $0,5 \mathrm{mg} / \mathrm{ml}$, diluídos no tampão do substrato (12\% de dietanolanina, 0,25\% de azida de sódio, pH 9,8). As leituras dos resultados foram efetuadas no aparelho Labsystem Multiskam MS, nos intervalos de 30 e $60 \mathrm{~min}$, no comprimento de onda de $405 \mathrm{~nm}$. As amostras com valores de absorbância duas vezes e meia dos valores registrados nos controles negativos (amostras sadias), foram consideradas positivas quanto à presença do vírus.

\section{Análise da sobrevivência do PLYV em sementes per si}

Após 15 dias de secagem, 456 sementes (273 com e 183 sem mucilagem) foram testadas por Elisa indireto para avaliação da presença do PLYV. As sementes foram, individualmente, maceradas em presença de tampão de cobertura na proporção de 1:10 (p/v) e, em seguida, 100 ìl do extrato obtido de cada semente foram adicionados em cada orifício da placa que foi incubada por $2 \mathrm{~h}$ a $37^{\circ} \mathrm{C}$. As etapas subseqüentes seguiram o protocolo descrito anteriormente.

\section{Avaliação da presença do PLYV no tegumento e no embrião de sementes}

Embriões de 1.128 sementes provenientes de frutos infetados e tegumentos de outras 670 sementes dos mesmos frutos foram testados por Elisa indireto. Em todos os testes, foram usados, como controle negativo, embriões e tegumentos de sementes de frutos sadios e, como controle positivo, extratos de casca dos frutos infetados. As sementes foram postas para intumescer em placas de Petri, contendo dupla camada de papel de filtro, devidamente esterilizados sob radiação ultravioleta, durante cinco dias, no escuro, em condições de laboratório. As sementes intumescidas foram seccionadas individualmente com o auxílio de bisturi esterilizado para a retirada do embrião e separação do tegumento. Cada parte da semente foi individualmente macerada na presença do tampão de amostra, na proporção de $1: 10(\mathrm{p} / \mathrm{v})$ e testada por Elisa indireto, usando-se extrato de embrião ou tegumento por orifício.

\section{Estudo da transmissibilidade do PLYV por mãos contaminadas}

Mudas sadias de mamoeiro com idade entre 30 e 40 dias foram inoculadas mecanicamente, através do contato de mãos contaminadas pelo PLYV, de acordo com os seguintes tratamentos: 1) inoculação por mãos contaminadas com folhas infetadas através da maceração das folhas em mãos umedecidas com água destilada; 2) inoculação por mãos contaminadas com folhas infetadas, e lavadas com água corrente, e 3) inoculação com mãos molhadas com água destilada (testemunha).

Folhas de 104 plantas foram inoculadas com mãos contaminadas com PLYV, folhas de outras 116 plantas foram inoculadas com mãos contaminadas com PLYV e lavadas em água corrente durante $30 \mathrm{~s}$ e folhas de 25 plantas foram friccionadas com as mãos umedecidas com água destilada (testemunha). As inoculações foram realizadas pela fricção de mãos contaminadas, com PLYV ou não, na superfície adaxial das folhas jovens de mamoeiros sadios.

As observações de possíveis sintomas foram realizadas semanalmente e 25 dias após as inoculações, as mudas foram testadas por Elisa indireto.

De um total de 672 sementes de frutos infetados com PLYV, envolvendo plântulas, verificou-se, mediante a avaliação sorológica, a ausência do vírus em todas as 310 plântulas e 362 mudas, com 30 dias de idade, demonstrando a não transmissibilidade do PLYV por semente (Tabela 1). Nas 456 sementes per si testadas, verificou-se a presença do vírus pelo teste de Elisa indireto em 49 sementes (32 com mucilagem e 17 sem mucilagem), representando um total de $10,74 \%$ das sementes testadas. Estes resultados indicam que o PLYV está presente em uma das camadas dos tecidos externos ao embrião da semente sem, no entanto, ser transmitido para plantas jovens (Tabela 1). De outra parte, a presença do PLYV não foi detectada nos embriões das 1.128 sementes testadas, confirmando sua ausência no tecido embrionário da semente, o que explica os resultados negativos nos testes de plântulas e de mudas produzidas a partir de sementes de frutos infetadas (Tabela 1). Contudo, o vírus foi constatado no tegumento de 112 das 670 sementes avaliadas, comprovando que, a presença do PLYV em sementes de mamão está restrita à casca (Tabelas 1 e 2).

A ausência do vírus em embriões de sementes de frutos infetados (Tabela 2) constitui uma indicação da não transmissibilidade do PLYV por sementes, pela forma embrionária, justificando a não transmissão do PLYV para plântulas e mudas oriundas de sementes de frutos infetados (Tabela 1). Segundo Martelli (1981), a transmissão embrionária por sementes é rara para os vírus pertencentes ao gênero Tombusvirus. Segundo van Regemontel et al. (2000), os vírus da família Tombusviridae, gênero Tombusvirus, são facilmente transmitidos por ações mecânicas no campo e muitas espécies podem ser encontradas no meio ambiente, água e solo, a partir de onde podem ser adquiridos pelas raízes das plantas sem o auxílio de vetores. De outra parte, a presença do PLYV no tegumento (Tabela 
2) pode constituir fontes de vírus nas proximidades do sistema radicular das mudas, possibilitando sua eventual penetração por ferimentos dos tecidos radiculares, como é o caso do Tobacco mosaic virus (TMV), gênero Tobamovirus (Walkey, 1985)..

Os resultados negativos do plantio direto com sementes de frutos infetados com e sem mucilagem mostram a impossibilidade de o PLYV penetrar ou se manter ativo nos tecidos embrionários, uma vez que as plântulas e mudas originadas não foram infetadas pelo mesmo (Tabela 1). Podese concluir, portanto, que o PLYV não está presente nos tecidos embrionários de sementes de frutos infetados, não sendo, portanto, transmitido através da prática do plantio direto de sementes.

A avaliação da transmissão do PLYV por mãos contaminadas, simulando as condições de campos de produção de mamão, demonstrou grande estabilidade do PLYV em permanecer ativo, aderido às mãos, mesmo após lavagem em água corrente. Por sintomatologia e confirmação sorológica, o PLYV foi transmitido para 19 das 220 plantas inoculadas, sendo 13 por mãos contaminadas sem lavagem e seis por mãos contaminadas e lavadas. A lavagem com água corrente reduz sem, no entanto, eliminar a carga viral e a estabilidade do vírus (Tabela 3). Mesmo após a lavagem das mãos, o vírus foi transmitido para mais de $5 \%$ das plantas, confirmando sua elevada estabilidade e facilidade de transmissão mecânica. Apesar de o percentual de transmissão

TABELA 1 - Resultados da análise sorológica de sementes com e sem mucilagem de frutos de mamoeiro (Carica papaya) infetadas por "Papaya lethal yellowing virus" (PLYV), através de testes de Elisa indireto de sementes per si, de plântulas e de mudas

\begin{tabular}{lcc}
\hline \multirow{2}{*}{ Tratamento } & \multicolumn{2}{c}{ Número de amostras } \\
\cline { 2 - 3 } & Com mucilagem & Sem mucilagem \\
\hline Sementes per si & $273 / 32^{*}$ & $183 / 1 *$ \\
Plântulas & $136 / 0$ & $174 / 0$ \\
Mudas & $210 / 0$ & $152 / 0$ \\
\hline
\end{tabular}

* Numerador - número de amostras testadas; denominador - número de amostras com PLYV

TABELA 2 - Resultados da avaliação por Elisa indireto, da presença de "Papaya lethal yellowing virus” (PLYV) em embrião e tegumento de sementes de frutos de mamoeiro (Carica papaya) infetados

\begin{tabular}{lc}
\hline \hline Tratamento & Número de sementes \\
\hline Embrões de sementes de frutos infetados & $1.128 / 0(0 \%)^{*}$ \\
Tegumentos de de se,emtes de frutos infetados & $670 / 112(16,7 \%)$ \\
Embriões de sementes de frutos sadios & $210 / 0(0 \%)$ \\
Tegumentos de sementes de frutos sadios & $130 / 0(0 \%)$
\end{tabular}

* Numerador - número de sementes testadas; denominador - número de sementes com PLYV (\% de transmissão)
TABELA 3 - Transmissão do "Papaya lethal yellowing virus" (PLYV) por mãos contaminadas com extrato de folhas de mamoeiro (Carica papaya) para mudas de mamoeiro, avaliadas por Elisa indireto

\begin{tabular}{lc}
\hline \hline Tratamento* & $\begin{array}{c}\text { Mudas inoculadas/Mudas } \\
\text { infetadas (\% de transmissão) }\end{array}$ \\
\hline Mãos contaminadas & $104 / 14(12,5 \%)$ \\
Mãos contaminadas e lavadas & $116 / 6(5,2 \%)$ \\
$\begin{array}{l}\text { Testemunhas: mãos com extratos } \\
\text { de plantas sadias }\end{array}$ & $25 / 0(0 \%)$ \\
* Contaminação das mãos de acordo com a metodologia discutida no texto
\end{tabular}

ter sido relativamente baixo, a preservação da integridade física e biológica do vírus é um dos principais fatores que favorecem sua disseminação pela ação do homem, usando instrumentos de corte ou as próprias mãos no manuseio de frutos e de folhas de plantas infetadas com o PLYV e plantas sadias (Camarço et al., 1998). Tudo isso indica a necessidade de cuidados adicionais com a assepsia das mãos e das ferramentas agrícolas, como forma complementar de controle (Lima et al., 2001; Lima \& Lima, 2002a, 2002b), à semelhança do que é recomendado para o TMV na cultura do tomateiro (Lycopersicon esculentum L.) (Walkey, 1985).

\section{REFERÊNCIAS BIBLIOGRÁFICAS}

ALMEIDA, A.M.R. \& LIMA, J.A.A. Técnicas sorológicas aplicadas a fitovirologia. In: Almeida, A.M. R. \& Lima, J.A.A. (Org.) Princípios e técnicas de diagnose aplicados em fitovirologia. 1 ed. Fortaleza, 2001, v. 1, pp.33-62.

CAMARÇO, R.F.E.A. Transmissão e sobrevivência do vírus do amarelo letal do mamoeiro Carica papaya L. Dissertação de Mestrado UFRP, Recife, 1997.

CAMARÇO, R.F.E.A., LIMA, J.A.A. \& PIO-RIBEIRO, G. Transmissão e presença em solo do "Papaya lethal yellowing virus”. Fitopatologia Brasileira 4:453-458. 1998.

KITAJIMA, W., OLIVEIRA, F.C., PINHEIRO, C.R.S., SOARES, L.M., PINHEIRO, K., MADEIRA, M.C. \& CHAGAS, M. Amarelo letal do mamoeiro solo no estado do Rio Grande do Norte. Fitopatologia Brasileira 17:282-285. 1992a.

KITAJIMA, W., REZENDE, J.A.M., VEJA, J. \& OLIVEIRA, F.C. Confirmada a identidade do vírus isométrico encontrado em mamoais do Rio Grande do Norte como sendo o amarelo letal do mamoeiro solo. Fitopatologia Brasileira 17:336-338. 1992b.

LIMA, J.A.A. \& SANTOS, C.D.G. Isolamento de possível estirpe do vírus do amarelo letal do mamoeiro no Ceará. Fitopatologia Brasileira 16:27. 1991. (Resumo)

LIMA, R.C.A. \& LIMA, J.A.A. Guerra às viroses. Cultiar Hortaliças e Frutas III:30-33. 2002a.

LIMA, R.C.A. \& LIMA, J.A.A. Viroses em mamoeiro e alternativas de controle. Secretaria da Agricultura Irrigada, Fortaleza, Boletim Técnico, 2002b. 
LIMA, R.C.A., LIMA, J.A.A., SOUZA JR., M.T., PIO-RIBEIRO, G. \& ANDRADE, G.P. Etiologia e estratégias de controle de viroses do mamoeiro no Brasil. Fitopatologia Brasileira 26: 689702. 2001.

LORETO, T.J.G., VITAL, A. F. \& REZENDE, J.A.M. Ocorrência de um amarelo letal do mamoeiro solo no Estado de Pernambuco. O Biólogo 49:275-279. 1983.

MARTELLI, G.P. Tombusvirus. In: Kurstak, E. (Ed.) Handbook of plant infections \& comparative diagnosis - North Amsterdam Holland Biomedical Press, 1981, pp.61-91.

SILVA, A.M.R., "Papaya lethal yellowing virus”: Caracterização biológica e molecular (Tese Mestrado), Brasília, Universidade de Brasília. 1996.

SILVA, A.M.R., KITAJIMA, E.W. \& RESENDE, R.O. Nucleotide anda mino acid analysis of the polymerase and the coat protein genes of the papaya lethal yellowing virus. Virus: Review and Research 11:196. 2000. (Abstract)

TEIXEIRA, M.G.C. Levantamento da incidência de vírus em mamoeiro (Carica papaya L.) em municípios do Rio Grande do Norte. Dissertação de Mestrado, Escola Superior de Agronomia de Mossoró. 1997.

VAN REGENMORTEL, M.H.V., FAUQUET, C.M., BISHOP, D.H.L., CARSTENS, E.B., ESTES, M.K., LEMON, S.M., MANILOFF, J., MAYO, M.A., MCGEOCH, D.J., PRINGLE, C.R. \& WICKNER, R.B. Wickner. Virus Taxonomy. Seventh Report of the International Committee on Taxonomy of Viruses. Academic Press. San Diego. 2000.

WALKEY, D.G.A. Applied Plant Virology. Londres. Heinemam. 1985. 